\title{
SABERES E PRÁTICAS DO ACOMPANHAMENTO TERAPÊUTICO COM CRIANÇAS: UMA REVISÃO BIBLIOGRÁFICA
}

\author{
Knowledge and Practices of Therapeutic Accompaniment with Children: a Literature Review \\ Conocimientos y Práticas de Accompañamiento Terapéutico con Niños: \\ uma Revisión de la Literatura
}

\author{
ANa LaURA Batista \\ TATYANNe Couto Flor \\ Ricardo Wagner Machado da SiLVeira
}

\begin{abstract}
Resumo: Esta pesquisa trata do Acompanhamento Terapêutico com crianças e sua importância se deve, dentre outras coisas, à escassez de publicações sobre a temática. Buscamos compreender como se dá o Acompanhamento Terapêutico com essa população, realizando uma pesquisa bibliográfica a esse respeito. Fizemos uma revisão bibliográfica a partir das produções científicas brasileiras dos últimos 14 anos (2001-2015), considerando artigos científicos e dissertações de mestrado. Foi utilizado o método de pesquisa bibliográfica, pautado na revisão sistemática, meta análise e análise de conteúdo das publicações encontradas. Na realização dessa análise, foram percebidos diferentes cenários de práticas do Acompanhamento Terapêutico com crianças, tendo maior destaque aquelas realizadas no contexto escolar e alguns poucos trabalhos em cenários como abrigos, centros de convivência, programas com atividades especializadas e a cidade propriamente dita. A partir da revisão bibliográfica percebemos o quão escassa é a produção bibliográfica sobre a temática, no entanto, percebemos também a riqueza de possíveis campos de atuação do acompanhante terapêutico com crianças. Outro aspecto que nos chamou a atenção foi a falta de estudos e reflexões sobre o trabalho de AT em relação às famílias de crianças acompanhadas.
\end{abstract}

Palavras-chave: Acompanhamento terapêutico; Criança; Clínica; Inclusão escolar; Família; Revisão bibliográfica.

Abstract: Due to the scarcity of studies on Therapeutic Accompaniment (TA) with children, recognizing the importance of contributing to the study on the subject, we seek to understand how the TA works with this population, by performing a bibliographic research about the topic. Therefore, the present study is done through a literature review from the Brazilian scientific productions in the last 14 years (2001-2015), considering scientific articles and dissertations. It is used the bibliographic research method, based on the systematic review, meta-analysis and content analysis from other publications. In conducting this analysis, different scenarios of TA practice with children were recognized, with more emphasis to those carried out in the school context and a few papers in scenarios such as shelters, community centers, programs with specialized activities and the city itself. Based on the literature review we realized how scarce the publications are, related to this paper. However, we also realized the richness of possible action fields of TA with children. Another aspect that caught our attention was the lack of studies and reflections on the TA work in relation to the families who have children accompanied.

Keywords: Therapeutic accompaniment; Clinical; Children; School inclusion; Family; Literature research.

Resumen: Esta investigación aborda el Acompañamiento Terapéutico con los niños y su importancia se debe, entre otras cosas, la escasez de publicaciones sobre el tema. Buscamos entender cómo es el Acompañamiento Terapéutico con esta población, la realización de una revisión de la literatura al respecto. Hicimos una revisión de la literatura de las producciones científicas brasileñas de los últimos 14 años (2001-2015), teniendo en cuenta los trabajos científicos y tesis. Se utilizó el método de la literatura, con base en la revisión sistemática, meta análisis y análisis del contenido de las publicaciones encontradas. Al llevar a cabo este análisis, se percibieron diferentes escenarios de las prácticas de acompañamiento terapéuticas con niños, con más énfasis las llevadas a cabo en el contexto de la escuela y algunos trabajan en entornos tales como refugios, centros comunitarios, programas con actividades especializadas y de la propia ciudad. A partir de la revisión de la literatura nos damos cuenta de lo poco que está en los escritos sobre el tema, sin embargo, también nos damos cuenta de la gran cantidad de posibles campos de actividad del acompañante terapéutico con niños. Otro aspecto que nos llamó la atención fue la falta de estudios y reflexiones sobre el trabajo de AT en relación con los niños acompañados de familias.

Palabras clave: Acompañamiento terapéutico; Clinica; Niño; La inclusion escolar; La família; Revisión literaria.

\section{Primeiras palavras}

Esta pesquisa trata do Acompanhamento Terapêutico $\left(\mathrm{AT}^{1}\right)$ com crianças, buscamos compreender como se dá o

\footnotetext{
Utilizaremos neste texto a sigla AT para Acompanhamento Terapêutico (e at para acompanhantes terapêuticos).
}

AT com essa população, realizando uma pesquisa bibliográfica a esse respeito. De antemão, esclarecemos que a pesquisa refere-se a um projeto de iniciação científica e contou com duas alunas do curso de graduação em Psicologia como pesquisadoras, sendo uma delas, bolsista de iniciação científica da FAPEMIG, instituição à qual agradecemos o apoio recebido. 
A partir dos ideais dos movimentos da reforma psiquiátrica ${ }^{2}$, há uma mudança na concepção de doença mental, principalmente relacionado ao dogma da exclusão. Frente a esse cenário, surge também uma nova modalidade clínica denominada Acompanhamento Terapêutico. O papel do acompanhante terapêutico (at) foi sendo delineado no início da década de 70, na Argentina, dentro das chamadas equipes terapêuticas de abordagem múltipla. Tais equipes atendiam pacientes severamente perturbados e com histórico de fracasso em outros tipos de tratamento (Mauer \& Resnizky, 1987).

(...) E aí foi aquela avalanche de iniciativas - abrir as portas dos manicômios, formar equipes multiprofissionais, criar ambulatórios de saúde mental, hospitais-dia, etc. -, diferentes territórios que, somados, aumentavam as chances da loucura libertar-se da sua condição de existência doente. Depois veio a necessidade de construir mediações não só entre esses vários territórios, mas também entre cada um deles e o da família, entre todos eles e a paisagem da cidade - era preciso criar possibilidades reais de vida não doente. A figura do acompanhante terapêutico (at) se delineia como uma das atualizações dessa necessidade (...). (Rolnik, 1997, p. 83-84)

O trabalho de AT visa, então, ofertar ao paciente oportunidades de estar e circular no social, fato que lhe foi retirado historicamente. $\mathrm{O}$ at tem como função ajudar o sujeito no seu processo de inserção nos espaços urbanos, facilitando a ele a circulação e os encontros de acordo com a sua capacidade criativa, primando pela preservação de seus recursos e possibilidades e não pela modificação da estrutura psíquica do paciente (Porto \& Sereno, 1991). O AT não pode ser reduzido a uma modalidade de intervenção clínica secundária. Em muitos casos é fundamental pois o at entra no campo da experiência do acompanhado para lhe ofertar "um lugar comunitário, ponto de partida para o gesto que constitui o porvir" (Antúnez, Barreto \& Safra, 2011, p. 17). Os autores nos apresentam o caso de um senhor de 66 anos com melancolia esquizofrênica acompanhado por Eugène Minkowski durante sessenta dias em tempo integral, para nos mostrar o quanto a presença do at e o convívio possibilitado a partir dessa presença e tempo, são elementos fundamentais para o diagnóstico e a terapêutica.

(...) não podemos conservar uma atitude médica 24 horas por dia; acabamos por atuar a respeito do doente com outras pessoas que o rodeiam. (...) É como se duas melodias radicalmente desarmônicas fossem executadas simultaneamente e se estabelecesse, além

\footnotetext{
A reforma psiquiátrica brasileira luta pelo fim do modelo manicomial e sua substituição pela Rede de Atenção Psicossocial, com vistas à desospitalização e desinstitucionalização da loucura; resgate da cidadania e reinserção psicossocial dos usuários do SUS.
}

do mais, uma certa equivalência entre as notas de um e do outro (...) Minha companhia o ajuda em certa medida, porque sei o que ele sabe, e isso lhe permite falar abertamente comigo; se estive ausente, ele necessita comunicar-me os descobrimentos que fez durante minha ausência. (Minkowski, 1970, conforme citado por Antúnez, Barreto \& Safra, 2011, p. 16)

Dentre tantas atribuições, o AT tem um compromisso ético e político relacionado à desinstitucionalização da loucura, juntamente com um compromisso estético de criação de novos modos terapêuticos de se relacionar com o paciente. $\mathrm{O}$ at seria então:

[...] como um intercessor a favor da constituição de novos territórios de vida e de convivência a partir da estratégia de desvio, de criação/encontro de saídas inéditas, conexões com territórios até então inexplorados na vida social da pessoa e que possam servir para escapar do que está instituído e cristalizado na vida do paciente institucionalizado. Desviando e fazendo desviar almeja-se a abertura para o encontro com o novo, o inusitado. (Silveira, 2009, p. 237)

O AT encontra-se em grande expansão, a qual muitos campos de atuação ainda podem ser aprofundados e ampliados. Por ser uma prática peculiar frente aos outros dispositivos clínicos, a mesma exige que o at busque conhecimentos e novos modos de intervenção de acordo com a especificidade de cada acompanhado e seu entorno social. Sabe-se que o público adulto tem sido a principal demanda a qual o AT tem atendido, sendo assim, a literatura pouco se reservou a tratar do AT na infância. Esta escassez de publicações talvez reflita a quase ausência de olhares para a infância ao longo da história, de modo que a luta pelo cuidado, pelo tratamento e contra a exclusão de crianças com transtornos mentais graves e com deficiência, ocorreu tardiamente. Com as atuais conquistas da clínica ampliada, fortemente compromissada com o tema da inclusão social, o at se aventura a acompanhar a loucura mais uma vez, indo agora às escolas.

Os movimentos de inclusão escolar são muito provavelmente filhos legítimos da luta antimanicomial. Se para os adultos esta última representou a queda dos muros dos hospitais e o esforço de integração na comunidade, "para as crianças a luta antimanicomial representou a bandeira da integração escolar e a guerra contra as escolas especiais, segregacionistas segundo aquela corrente. Assim assiste-se hoje à retomada da escolarização da criança psicótica” (Kupfer, 1997, p. 56). Diante da escassez de trabalhos sobre AT com crianças, do reconhecimento da importância de contribuir no estudo sobre a temática, e guiados pela curiosidade de compreender como se dá o AT com essa população, iniciamos uma pesquisa bibliográfica referente a temática e percebemos a necessidade de se realizar uma sistematização dessas publicações. 
Na tentativa de expor o que está sendo publicado e como vem sendo realizado o trabalho de AT com crianças a partir desta fonte de dados, o presente estudo se dá por meio de uma revisão bibliográfica a partir das produções científicas brasileiras dos últimos 14 anos, considerando artigos científicos e dissertações de mestrado. Analisar sistematicamente tais produções científicas pode possibilitar que se compreenda melhor, pelo menos uma parte da realidade referente ao desenvolvimento científico sobre o tema na atualidade.

Na realização dessa análise, foram percebidos diferentes cenários de práticas do AT com crianças, tendo maior destaque aquelas realizadas no contexto escolar e alguns poucos trabalhos em cenários como abrigos, centros de convivência, programas com atividades especializadas e a cidade propriamente dita.

\section{Percurso metodológico}

Foi utilizado o método de pesquisa bibliográfica, pautado na revisão sistemática, metanálise e análise de conteúdo, a partir do levantamento de publicações de artigos científicos e dissertações de mestrado nos últimos 14 anos, ou seja, de 2001 a 2015. A revisão sistemática é considerada uma metodologia de estudo científico que utiliza diferentes estratégias para se ter precaução frente aos vieses, pois é um processo sistemático planejado $a$ priori, estabelecendo critérios para cada etapa do processo. Um fator importante a ser destacado e que interfere diretamente na recuperação das referências publicadas é o modo que se deu a busca, uma vez que as fontes de informação têm peculiaridades que exigem estratégias específicas e diferentes a serem elaboradas (Benatto, 2014).

A meta análise, segundo Luiz (2002), é uma técnica que se propõe a integração dos resultados de um conjunto de estudos independentes, voltando-se para um mesmo trabalho. Tal técnica permite transformar os resultados de vários estudos escolhidos na literatura especializada e sintetizar as conclusões ou formular uma nova conclusão a partir dessas.

A análise de dados será feita através do método da análise de conteúdo, que possui objetivos que permitem a superação da incerteza e o enriquecimento da leitura, bem como ter uma função heurística (tentativa exploratória visando descobertas) e de administração da prova (análise sistemática para verificações). Segundo Bardin (2009), a análise de conteúdo se refere a:

Um conjunto de técnicas de análise das comunicações visando obter por procedimentos sistemáticos e objetivos de descrição do conteúdo das mensagens indicadores (quantitativos ou não) que permitam a inferência de conhecimentos relativos às condições de produção/recepção (variáveis inferidas) destas mensagens. (p. 44)
Bardin (2009) relata que a análise realizada pelo investigador deve ter seu enfoque na criação de um jogo de operações analíticas. Tais operações podem ser mais ou menos adaptadas de acordo com o que se procura resolver, cabendo ao investigador utilizar uma ou várias, de modo complementar, a fim de que facilite a busca de resultados que possam ser validados, determinando uma interpretação bem fundamentada. Para se alcançar os objetivos desse estudo, foram revisadas as publicações acadêmicas sobre AT com crianças a partir de artigos científicos publicados em periódicos científicos e dissertações de mestrado.

A busca de produções exclusivamente nacionais se deu frente às seguintes combinações de palavras-chave: acompanhamento + terapêutico, acompanhamento terapêutico + criança, acompanhamento terapêutico + infância, no título, subtítulo ou resumo das produções, com data de publicação superior a 2001.

As fontes acessadas foram: $1^{\mathrm{a}}$ ) BVS (Biblioteca Virtual em Saúde), PePSIC (Periódicos Eletrônicos em Psicologia), SCIELO (Scientific Eletronic Library Online) e LILACS (Literatura Latinoamoericana e do Caribe em Ciências da Saúde); $2^{\text {a }}$ leitura das referências bibliográficas das produções acadêmicas a fim de se encontrar materiais que não foram selecionados nessas bases de dados; $3^{\mathrm{a}}$ ) verificação dos Currículos Lattes (http://lattes.cnpq. br/) dos pesquisadores e orientadores de pesquisa, para verificar se os mesmos participaram de outros estudos sobre a temática que não haviam sido encontrados nas buscas anteriores; $4^{\mathrm{a}}$ ) verificação das referências bibliográficas citadas em uma dissertação de mestrado que realizou uma revisão bibliográfica sobre a clínica do AT no contexto brasileiro.

As produções encontradas primeiramente foram analisadas com a leitura do título e subtítulo para esclarecer se faziam parte do universo de produções procurados nesse estudo. Foram lidos também os resumos e palavras-chave de todas os materiais que não haviam sido incluídos na primeira análise, a fim de enquadra-los ou não nessa pesquisa. Não foram considerados textos publicados em revistas de divulgação ampla, jornais, boletins informativos e outros tipos de produções informais; além de não se incluir publicações de anais de congresso, publicações referentes a especialização e formação em AT e monografias/ artigos de conclusão de cursos de graduação.

Tais exclusões se justificam pela possível dificuldade de acesso a esses materiais que geralmente são restritos a consulta nos locais onde foram produzidos, além de que a produção cientifica em anais de congresso é tamanha e poderia levar a um distanciamento da temática e sua especificidade. Foram excluídos também livros e capítulos de livro sobre a temática desse estudo, devido à natureza física desse recurso, o que necessitaria de se ter acesso a todas as obras para analisá-las.

Entende-se que o recorte feito é um limitador da presente pesquisa, devido ao prazo a ser cumprido pela proposta de iniciação científica. Entretanto, fica em aberto 
novas perspectivas de pesquisas para o futuro que abarquem, por exemplo, produções que não sejam nacionais e referentes a capítulos de livros e livros acerca da temática.

\section{Refletindo sobre o AT com crianças}

Considerando a Constituição Federal de 1988 e o Estatuto da Criança e do Adolescente (ECA) de 1990, é dever do Estado e das famílias oferecerem condições para que todas as crianças possam exercer o direito de frequentarem escolas regulares. Nesse sentido, também deve ser garantido o "atendimento educacional especializado aos portadores de deficiência, preferencialmente na rede regular de ensino", segundo a Lei no 8.069, de 13 de julho de 1990 (Brasil, 1990).

Em 17 de novembro de 2011 foi assinado o decreto $\mathrm{n}^{\circ}$ 7611 pela presidenta Dilma Rousseff, o qual efetiva algumas diretrizes para a educação das pessoas consideradas público-alvo da educação especial. Dentre as diretrizes do decreto, uma delas visa efetivar a educação no sentido de oferecer o suporte necessário ao portador de necessidades especiais no sistema educacional geral (Brasil, 2011). Ao situar a noção de inclusão, deparamo-nos inevitavelmente com sua suposta antítese, a ideia de exclusão, historicamente vivenciada em nossa sociedade para além dos muros da escola. As relações sociais ao longo do tempo são marcadas, por um lado, por aqueles que excluem e decidem quem será incluído, e, do outro lado, os excluídos (Kibrit, 2013). Para Kupfer (1997), a educação regular se constitui como um produtor de exclusão do diferente, em que práticas pedagógicas criam uma categoria de crianças que serão excluídas.

Promover a inclusão não significa, portanto, passar a olhar todos como iguais, transformando o diferente em igual, como se a diferença determinasse a exclusão. $\mathrm{Na}$ realidade, defende-se uma mudança paradigmática nas formas de pensar, que seja a favor da diferença (consequentemente da singularidade) e, ao mesmo tempo, da igualdade - no sentido de garantir os diretos e deveres universais a todos os cidadãos perante a lei.

Desse modo, lutar pela inclusão significa lutar pela diferença, entendendo-a não como inerente à exclusão, mas como aspecto constitutivo da sociedade e dos indivíduos, enriquecedor para esta (Kibrit, 2013). Assim, não basta que a escola coloque para dentro uma criança diferente, deve-se buscar ser inclusiva a partir de transformações estruturais em que o sentido de diferença seja incorporado em seu cotidiano educativo (Kupfer, 2010). Além disso, para que a inclusão seja plena e o desenvolvimento acadêmico e social seja maximizado nos diferentes ambientes, busca-se adotar estratégias de suporte individualizado. O decreto esclarece também que o público-alvo da educação especial são pessoas com deficiência, com transtornos globais do desenvolvimento e com altas habilidades ou superdotação.
A partir das conquistas legais acerca da inclusão, novas demandas no contexto escolar surgem, sendo uma delas o reconhecimento da necessidade de se ter como apoio profissionais que efetivem a inclusão. Daí um dos motivos para o interesse pelo tema específico do AT na escola. Nesse contexto, o at se coloca como possibilidade de auxílio na escolarização de crianças com transtornos graves, se orientando em prol da inclusão dessas e em consonância com a legislação vigente.

Dentre as possíveis estratégias para se efetivar a inclusão, o AT vai delineando seu lugar no contexto escolar. Em Acompanhamento terapêutico e educação inclusiva, a autora Sereno (2006) relata um projeto de inclusão, articulando saúde e educação, em que o AT funcionava como um dos dispositivos da rede, frequentando a escola e realizando oficinas psicopedagógicas com a turma, a fim de trabalhar a questão das diferenças. Juntamente com o AT, a rede também propunha cursos de formação relacionados a inclusão com os profissionais envolvidos, e reuniões entre a equipe de saúde mental e a equipe escolar. Promovia-se práticas inclusivas de uma maneira mais ampla, em que o objetivo do at no contexto escolar seria o de promover educação inclusiva de qualidade, sustentando-se por uma "rede de compromissos coletivos".

Nos trabalhos de Coelho (2007) e Berlinck e Fraguas (2001), percebe-se que esse trabalho em rede dentro do contexto escolar não se evidencia. Vê-se que as estratégias inclusivas comumente se limitam à figura do at ou a algum auxiliar que ofereça apoio individualizado a fim de maximizar o desenvolvimento acadêmico e social de certas crianças com transtornos mentais graves. Berlinck e Fraguas (2001) relatam um caso de AT que aconteceu em uma escola (especificamente uma pré-escola regular da rede particular), em que o at foi requisitado para o trabalho com crianças com graves transtornos psíquicos que possuem dificuldades na interação e na aprendizagem. Definia-se o trabalho do AT tanto no interior da sala de aula, quanto fora dela, envolvendo todo o período escolar, de modo que um dos objetivos era integrar a criança ao grupo e nas atividades da turma, respeitando seus limites e potencialidades. No entanto, a expectativa da escola com o trabalho de AT não era que esse exercesse uma função terapêutica com a criança, mas que cumprisse um papel pedagógico de adaptar a criança ao processo de escolarização instituído.

Em outra experiência de AT na escola, a demanda do estabelecimento de ensino também priorizava o caráter pedagógico a ser desempenhado pelo at. Presumia-se que seu trabalho deveria resultar na evolução da escolarização da criança, bem como na realização dos deveres escolares da mesma forma que seus colegas. Desse modo, o at se vê num conflito: de um lado, as exigências pedagógicas da escola e, de outro, a busca pessoal e profissional de um lugar em que o terapêutico fosse priorizado (Coelho, 2007). Assim, percebe-se um embate ao tratar do AT na escola: 
como a função pedagógica e terapêutica podem ser pensadas pelo at no contexto escolar e pela própria escola?

Diante dessa questão, constatou-se que para cumprir qualquer demanda pedagógica vinda da escola, seria necessário primeiramente se vincular à criança, sendo que a possibilidade desta criar um vínculo com o at significaria apostar na função terapêutica inerente ao trabalho, já que se constituiria uma mudança no modo de funcionamento da criança e de seus laços sociais. Entende-se, dessa forma, que a separação entre o terapêutico e pedagógico se dá apenas didaticamente, já que muitas vezes tais condutas se misturam e intercambiam (Berlinck \& Fraguas, 2001). Para ilustrar esta importante questão, podemos citar Coelho (2007) que considera que o AT na escola:

(...) exige do acompanhante a capacidade de suportar uma divisão interna a respeito do discurso terapêutico e do discurso pedagógico. Ser acompanhante terapêutico na escola implica ter "jogo de cintura” para saber oscilar entre uma postura mais pedagógica e uma postura mais terapêutica. Por um lado, o at deve estar disponível para ter uma postura mais pedagógica com a criança acompanhada, já que um dos objetivos desse trabalho é auxiliar o indivíduo na realização de tarefas do cotidiano, do qual a escola faz parte. Por outro deve ter sensibilidade para perceber quando o indivíduo acompanhado necessita de um amparo terapêutico que coloca de lado a atitude pedagógica. (p. 80)

O autor pontua sobre a possibilidade de a escola ter uma função pedagógica específica com alunos que vivenciam o processo de inclusão, privilegiando os benefícios emocionais de frequenta-la, ao invés de priorizar a adaptação da criança aos preceitos da educação institucionalizada. Certas escolas não se dão conta do fato de ser um lugar constitutivo na vida dos alunos, para além de um lugar somente de aprendizagem. É notório que o seu papel de educar é importante, no entanto, uma criança com grave sofrimento psíquico talvez não esteja preparada emocionalmente para processos de escolarização, sendo mais importante a oferta de experiências fundamentais como a interação com o outro, ou melhor, com os outros, para além do círculo familiar restrito e, por vezes enclausurante.

Segundo Sereno (2006), "estar na escola favorece novas possibilidades de sentido, articulação, encontro, que pode implicar em um novo posicionamento da criança que aí está se constituindo” (p. 176). Ainda segundo a autora, no que se refere à escolarização de crianças com transtornos graves, a inclusão pode beneficiar a aprendizagem fundamental que é a convivência, sendo esta acoplada com o aprender a aprender, a ser e a fazer. Nesse sentido, considerando a inclusão escolar um modo possível de estar e circular no social, esta empreende em si um campo terapêutico, já que ao se ofertar um lugar na escola, se atribui no imaginário um lugar social à criança, um lugar de sujeito (Kupfer, 1997).
Desse modo, atribui-se a importância que a escola em si possui no processo inclusivo, reforçando, assim, a ideia de que o lugar do at na escola não deve ser o de responsabilidade total pelo processo de inclusão de algumas crianças, tampouco de substituto do saber do professor. $\mathrm{O}$ at deve ser facilitador do processo inclusivo, criando condições para que a criança participe do universo escolar e se beneficie do processo educativo, sustentado pela convivência social.

Delinear o lugar do at junto a criança na escola, ajuda a pensar como ocorre seu papel de facilitar o processo inclusivo. Dentre as possíveis atribuições, este deve apresentar-se à criança como presença ativa, em que o corpo se presentifica no oferecimento de um tipo de referência e/ou acolhimento. Além disso, colocar-se como secretário e intérprete, operando como tradutor da ambiência, em que nomeia e significa as situações vivenciadas, beneficiando, dessa forma, o processo de subjetivação do acompanhado e a ligação com os elementos presentes na escola (Sereno, 2006).

Em suas ações, o at deve ser aquele que traz o outro para as situações cotidianas que até então ele estava alijado, por exemplo, chamando a criança a participar de uma conversa que diz respeito a ela; naqueles momentos frequentes em que o at é solicitado pela escola a tratar de questões que dizem respeito diretamente ao acompanhado. Agindo assim, o at procura desmantelar processos comunicacionais cronificados em que a criança não tem vez nem voz, pois sempre tem alguém a ocupar, de forma desmedida, o papel de seu porta-voz (Sereno, 2006).

$\mathrm{O}$ at também pode incentivar o professor a fazer intervenções em momentos de crise, remetendo-se a ele como aquele que tem um lugar de decisões na escola, da mesma forma que se deve dirigir a outros profissionais a partir das funções que lhes conferem no contexto institucional. Assim, as ações do at se orientam no sentido de fazer-se invisível, deixando de ser necessária a sua presença quando a criança e o coletivo da escola conseguem acolher, sustentar e se comprometer com as produções do acompanhado (Sereno, 2006).

Como anunciado anteriormente, para além do contexto escolar, encontramos o at com crianças acontecendo em outros cenários que se aproximam também de uma reflexão crítica e política da atuação do at em relação a infância, sua exclusão e inclusão social. O at adentra em estabelecimentos e na cidade acompanhando crianças com sofrimentos psíquicos graves com o objetivo de construir e ocupar espaços que se propõem à desinstitucionalização da loucura, constituir novos lugares de relação ao promover a oferta de laço social, em consonância com o compromisso ético, clínico e político ao qual essa clínica se propõe.

Um dos trabalhos encontrados intitulado "Acompanhamento terapêutico: andanças pelo dentro e o fora da instituição" se deu em um Abrigo Institucional de Proteção a Portadores de Necessidades Especiais, onde os ats 
problematizam a implicação política do seu trabalho em uma instituição caracterizada como total, entendendo sua atuação como articuladora da operacionalização da Reforma Psiquiátrica, promovendo assim a inclusão social de crianças com necessidade especiais.

O referido abrigo ainda passava por um processo de transição de sua organização e estrutura para se adequar ao que determina o ECA, ou seja, a mudança de um Abrigo Institucional para um Abrigo Residencial. Devido a isso os autores identificam característica marcantes de uma instituição total que comporta um grande número de crianças com necessidade especiais excluídas da sociedade por um longo período de tempo e onde não há espaço para o desejo e para a criação (Disconsi et al., 2013). O trabalho visou então que os sujeitos enclausurados entrassem em contato com o território para além dos muros do abrigo além de promover movimentos e intervenções que possibilitassem a produção de subjetividade e de singularidades dentro do estabelecimento. A atuação dos ats dentro do abrigo se iniciou com a sensibilização dos monitores e repensando as práticas de cuidados oferecidos por eles. Um tempo depois, os ats, as crianças e os monitores se aventuraram pelas ruas da cidade, se tornando visíveis aos olhos dos outros e acessando espaços e tempos até então inalcançáveis para elas. Numa sucessão de atos clínico-políticos, a cidade e os que nela habitam se transformam na medida em que conseguem abrigar e dar visibilidade aos invisíveis habitantes do abrigo institucional que foi se tornando residência, casa (Disconsi et al., 2013).

O estudo de Hermann (2010) defende a ideia de que o trabalho de AT tem a vocação de aproximar os sujeitos às ofertas de laço social. O autor coloca em questão a educação como um espaço de oferta de laço social a crianças com sofrimentos psíquicos graves e nos apresenta uma experiência em que o AT aconteceu em um Centro Educacional Unificado, no qual se tem uma escola pública, uma piscina, quadras esportivas, um teatro e um serviço da rede de saúde mental da cidade de São Paulo chamado CECCO - Centro de Convivência e Cooperativa.

Os CECCOs ocupam parques, praças e centros esportivos; buscam acolher e promover encontros heterogêneos, pois abarcam todas as demandas possíveis de usuários: crianças, adolescentes, idosos, portadores de necessidades especiais dentre outros. Ele é visto como possibilidade de criação de parcerias de tratamento em outros espaços institucionais, que não os habituais, podendo ser caracterizados também como instituições que auxiliam no tratamento de pessoas com graves comprometimentos emocionais (Hermann, 2010).

$\mathrm{O}$ at foi a essa instituição com a criança acompanhada a fim de "transitar por um espaço onde a livre circulação fosse premissa básica” (Hermann, 2010, p. 45), em que o acolhimento fosse a principal prioridade do serviço. At e acompanhada se depararam com um local que permitiu o exercício da convivência e cidadania por meio da arte, de forma que as oficinas que a criança participou foram locais importantes de autonomia e encontro com a heterogeneidade, na medida em que as pessoas que ali estavam tinham um ambiente propício para compartilhar desejos comuns e variáveis ao realizarem uma mesma tarefa (Hermann, 2010).

Outro estudo de caso tratava de uma criança em situação de vulnerabilidade social e em articulação com intervenções em Terapia Ocupacional. Os acompanhamentos se deram no Programa Permanente de Composições Artísticas e Terapia Ocupacional (PACTO), na casa da criança e em alguns espaços urbanos.

(...) a intervenção no território, que caracteriza o AT, fortalece recursos, amplia redes e facilita o acesso a lugares públicos. Segundo Castro (2007), um "setting flexível”, que se transforma constantemente, possibilita uma intervenção nas diversas áreas nas quais se desenvolve a ação do homem, como é proposto pela Terapia Ocupacional. O deslocamento por diferentes espaços amplia as possibilidades de relação, ação e criação, transformando a cidade em um verdadeiro espaço potencial. (Buelau et al., 2009, p. 167)

Tal estudo ressalta a importância do processo criativo para o desenvolvimento humano e entende que a clínica do AT tem como compromisso ético a valorização da vida diante da capacidade de criação, de modo que se entende a subjetividade como um constante processo de autoprodução, intrinsecamente relacionado com o campo cultural. Por fim, encontramos um texto que se dedica especificamente ao AT na cidade intitulado: As crianças na cidade e o Acompanhamento Terapêutico. O texto nos convoca a refletir sobre a função do at com crianças, defendendo a ideia de que este trabalho deve se articular com o urbano a fim de circular em espaços que vão além das redes sintomáticas permeadas por repetições automáticas que abarcam a vida das mesmas em suas casas (Meira, 2013).

A autora nos atenta para o fato de que o at, ao acompanhar uma criança na cidade, deve mergulhar no ritmo que a criança dispõe a explorar os locais, mostrando lugares invisíveis aos olhares adultos, já que sua temporalidade não é a mesma que os marca os passos acelerados daqueles. Para isso, o at é desafiado a se desprender de roteiros e técnicas preconcebidos, de tempo controlado e se lançar ao não-saber em meio às ofertas incessantes de consumismo que assolam todos os cantos da vida urbana, e assim "mergulhar na cidade, em suas vielas, becos, ladeiras, calçadas, encontrando o outro em espaços desconhecidos, capturando gestos e palavras, possibilita à criança o desdobramento de seu universo imaginário, a constituição de laços sociais (Meira, 2013, p. 42).

Além disso, segundo a autora, é condição sine qua non para trabalhar como at, a não adesão cega a diagnósticos e classificações sintomatológicas estandartizadas pelo discurso científico, sob o risco de enclausurar as crianças em rótulos psi que costumam resultar em processos de 
institucionalização e medicalização. O texto conta sobre uma experiência realizada na cidade de Porto Alegre: o projeto Cidade das crianças. Tal projeto é desenvolvido em espaços públicos e culturais da cidade com crianças de 4 a 11 anos de idade, de vários grupos sociais. Os profissionais que conduzem os encontros semanais são artistas, psicanalistas e psicólogos.

A autora descreve que é notório o prazer das crianças em se encontrarem em um espaço público sendo convocadas a inventarem diante poesias, histórias, teatro, passeios a lugares históricos e a eventos culturais. Cria-se um espaço então para o acolhimento do estranho, já que algumas pessoas param, observam e ousam em escutar as crianças, revisitando muitas vezes suas próprias infâncias. Assim, o trabalho do at na cidade acompanhando crianças perpassa pela descoberta e criação da cidade enquanto espaço que vai muito além do imaginário terrorífico apregoado pela mídia enquanto máquina paranoica de reprodução de clausuras e violências, para que nesse árduo e apaixonante caminho se possa ter experiências de trocas solidárias, alegres e coletivas, permitindo assim, à criança ser um cidadão capaz de exercer plenamente seu direito de ir e vir e assim, cada vez mais desejar e lutar pela sua e pela nossa liberdade (Meira, 2013).

Assim, o trabalho do at em diferentes estabelecimentos e espaços ofertados pela cidade possibilita a ampliação dos mapas de circulação dos acompanhados e a construção de vínculo nos vários cenários apresentados pelos autores pesquisados.

\section{Considerações finais}

A discussão sobre a inclusão e a exclusão social é essencial quando tratamos da clínica do AT, uma vez que a história do AT envolve as lutas pela desinstitucionalização da loucura e de toda e qualquer diferença que tende a ser excluída socialmente. Com o estudo do AT com crianças, é evidente que temos que considerar particularidades concernentes à clínica infantil e suas especificidades, e assim reafirmar seu compromisso ético e político com a desinstitucionalização e a clínica ampliada.

Com a realização da revisão bibliográfica sobre o tema, vê-se que os cenários nos quais o AT vem acontecendo com maior frequência são os estabelecimentos escolares - devido, principalmente, às recentes conquistas legais havendo também relatos de trabalhos nas cidades e em outros lugares, como abrigos e centros de convivência. No caso do at no contexto escolar, seu papel acaba por ser o de um facilitador da inclusão, o que não significa tratar todos como iguais e sim lutar pela diferença e pela singularidade de cada um (Sereno, 2006). A ideia é que o at crie condições para que a criança participe do cotidiano escolar e se beneficie dos processos educativos.

Nas experiências encontradas, uma problemática recorrente é: o que se exige do at na escola? Diante desta questão emerge um embate no at e nos outros atores que compõem o cenário, sobre a função pedagógica que lhe é demanda e a função terapêutica que ele, at, acredita dever ofertar. Sobre isso, o que se propõe é que haja um equilíbrio entre essas duas funções, em que o at tenha uma sensibilidade às necessidades do acompanhado, mantendo uma postura terapêutica em suas ações, e ao mesmo tempo possa ajudar o acompanhado nas tarefas escolares quando sentir ser possível intervir de um modo mais pedagógico (Coelho, 2007; Berlinck \& Fraguas, 2001).

Nesse sentido, o at é uma peça importante no processo inclusivo de crianças, atuando como mediador e facilitador para que a escola cumpra seu papel de ofertar um lugar à criança, um laço social. Apesar de algumas especificidades dos cenários explorados nesta pesquisa, o trabalho visa em todos eles abrir espaço e acolhida para a singularidade e para o laço social. Nos Centros de Convivência, o AT possibilita que novos e potentes encontros aconteçam para o acompanhado, uma vez que ultrapassa os já acostumados e estigmatizados espaços da saúde mental (Hermann, 2010). Da mesma forma que ao experimentar outros modos de estar e enxergar as crianças abrigadas, tratando-as em suas singularidades, possibilita que as crianças possam ocupar a cidade e que a sociedade as enxerguem e as reconheçam em sua existência.

Assim, o ser at envolve não só uma postura clínica, mas também um compromisso político e ético. Político quando faz da Pólis lugar de morada, de circulação e liberdade para as crianças que até então viviam institucionalizadas das mais diferentes formas pelos seus responsáveis. Ampliar os territórios existenciais nas cidades, possibilitando que a diferença possa ser constituinte e enriquecedora destas cidades que se tornam outras a partir daí. Ético quando há um compromisso, uma valorização da vida e do seu constante processo de criação e produção (Disconsi et al., 2013).

A partir da revisão bibliográfica realizada percebemos, e já o dissemos anteriormente, o quão escassa é a produção bibliográfica sobre a temática deste estudo, tal como nos mostra a revisão bibliográfica das publicações sobre o AT no Brasil no período de 1985 a 2013, publicado na dissertação de mestrado de Benatto (2014) e as poucas publicações encontradas ao longo deste estudo sobre AT com crianças. No entanto, percebemos também a riqueza de possibilidades na atuação do at com crianças. Um outro aspecto que nos chamou a atenção foi a falta de estudos e reflexões sobre o trabalho de AT em relação às famílias de crianças acompanhadas, já que nessa fase da vida as famílias têm papel preponderante e certamente serão protagonistas de todo AT que houver.

E assim finalizamos este despretensioso trabalho propondo novos começos, já que para nós ficou clara a necessidade de se desenvolver mais pesquisas e trocas de experiências acerca do tema AT com crianças, além de outros estudos que realizem revisão bibliográfica utilizando outras fontes, como por exemplo, capítulos de livros. 


\section{Referências}

Antúnez, A. E. A.; Barreto, K. D. \& Safra, G. Acompanhamento Terapêutico: contribuições de Minkowski. In: Antúnez, A. E. A. (Org.) (2011). Acompanhamento Terapêutico - casos clínicos e teorias. São Paulo: Casa do Psicólogo.

Bardin, L. (2009). Análise de Conteúdo. Lisboa, Portugal: Edições 70, LDA.

Benatto, M. C. (2014). A Clínica do Acompanhamento Terapêutico no Brasil: uma análise da produção científica de 1985 a 2013. Dissertação de Mestrado. Universidade Federal do Paraná, Curitiba, Paraná.

Berlinck, M. T. \& Fraguas, V. (2001). Entre o pedagógico e o terapêutico: algumas questões sobre o acompanhamento terapêutico dentro da escola. Estilos da Clínica. 6(11), 7-16.

Brasil (1990). Lei $n^{0}$ 8.069, de 13 de julho de 1990. Recuperado em 22 de outubro de 2014, de http://www.planalto.gov.br/ ccivil 03/leis/l8069.htm

Brasil (1911). Decreto $n^{\circ} 7611$, de 17 de novembro de 2011. Recuperado em 20 de novembro de 2014, de http://www.planalto.gov.br/ccivil_03/_ato2011-2014/2011/decreto/d7611.htm

Buelau, R. M.; Inforsato, E. A. \& Lima, E. M. F. A. (2009) Exercícios de sonhar junto: criatividade e experiências estéticas no acompanhamento de uma criança. Revista Terapia Ocupacional. 20(3), 164-170.

Coelho, C. F. M. (2007). Convivendo com Miguel e Mônica: uma proposta de Acompanhamento Terapêutico de crianças autistas. Dissertação de Mestrado. Instituto de Psicologia, Brasília, DF.

Disconsi A. M.; Cavedon B. Z.; Greff B. P.; Chassot C. S.; Galvão C. \& Hermann, M. C. (2010). Acompanhamento terapêutico, sua criação em uma montagem institucional de tratamento e as ofertas de laço social. Estilos da clínica, 15(1), 40-59.

Kibrit, B. (2013). Possibilidades e desafios na inclusão escolar. Revista Latinoamericana de Psicopatologia Fundamental, 16(4), 683-695.

Kupfer, M. C. M. (1997). Educação terapêutica: o que a psicanálise pode pedir à educação. Estilos da Clínica, 1(2), 53-61.

Kupfer, M. C. M. (2010). O sujeito na psicanálise e na educação: bases para a educação terapêutica. Revista Educação e Realidade. 35(1), 265-282.

Leães, M. L. \& Carvalho M. G. (2013) Acompanhamento Terapêutico: andanças pelo dentro e o fora da instituição. Psicologia \& Sociedade, 25(2), 65-72.

Luiz, B. A. J. (2002). Meta-Análise: definição, aplicações e sinergia com dados espaciais. Cadernos de Ciência e Tecnologia, 19(3), 407-428.

Mauer, S. K. \& Resnizky, S. (1987). Acompanhantes Terapêuticos e Pacientes Psicóticos: Contra a Enfermidade como Delito. Campinas: Papirus.

Meira, A. M. (2013). As crianças na cidade e o acompanhamento terapêutico. Psicologia \& Sociedade, 25(2), 41-45.
Porto, M. \& Sereno, D. (1991). Sobre acompanhamento terapêutico. In Equipe de Acompanhantes Terapêuticos do hospital-dia "A Casa" (Org.). A rua como espaço clínico: acompanhamento terapêutico (p. 23-31). São Paulo: Escuta.

Rolnik, S. Clínica Nômade. (1997). In Equipe de Acompanhantes Terapêuticos do Instituto A Casa (Org.). Crise e cidade: acompanhamento terapêutico. São Paulo: EDUC.

Sereno, D. (2006). Acompanhamento terapêutico e educação inclusiva. Psychê. X(18), 167-179.

Silveira, R.W.M. (2009) O Acompanhamento Terapêutico como estratégia de Atenção Psicossocial e suas interfaces com o trabalho do CAPS na cidade de Uberlândia-MG. In Mayorga, C.; Rasera, E. F. \& Pereira, M. S. (Orgs.) Psicologia Social. Sobre Desigualdades e Enfrentamentos. (p. 235-250) Curitiba: Juruá, 2009.

Ana Laura Batista - Aluna do curso de graduação do Instituto de Psicologia e pesquisadora no projeto de iniciação científica da Universidade Federal de Uberlândia.

Tatyanne Couto Flor - Aluna do curso de graduação do Instituto de Psicologia, pesquisadora no projeto de iniciação científica da Universidade Federal de Uberlândia e bolsista FAPEMIG.

Ricardo Wagner Machado da Silveira - Professor Doutor do Instituto de Psicologia e Pesquisador responsável pelo projeto de iniciação científica da Universidade Federal de Uberlândia. Endereço Institucional: Av. Pará, 1720, Campus Umuarama, Bloco 2C, sala 34, CEP 38401-136, E-mail: ricardo.silveira@ufu.br

Recebido em 01.06.2016 Primeira Decisão Editorial em 17.08.2016 Aceito em 06.10.2016 